\title{
Simultaneous Soft Tissue Sarcoma Excision and Prophylactic and Bony Fixation of the Upper Limb: Expediting Radiotherapy and Reducing Fracture Risk \\ Holmes WJM*
}

Department of Plastic Surgery, Alder Hey Children's Hospital, UK

\begin{abstract}
We present a case report of a 59-year old man with grade 3 leiomyosarcoma of the anterior deltoid. This case highlights the importance of dealing with these cases in a multidisciplinary team setting with both plastic and orthopedic surgeons.
\end{abstract}

\section{Introduction}

We present a case report of a 59-year-old right hand dominant fork-lift truck driver who presented to the Regional Sarcoma Unit at the Leeds General Infirmary with a rapidly enlarging painless mass in his right upper arm. Initial ultrasound revealed a lobulated mass with significant internal vascularity. Subsequent MRI demonstrated a large $7.5 \mathrm{~cm} \times 3.5 \mathrm{~cm} \times 3 \mathrm{~cm}$ heterogenous mass within the anterior deltoid and bicep brachii muscles of the right arm that was abutting the anterior surface of the humerus (Figure 1). Imaging was suspicious for a malignant tumour. Staging Computer Tomography scan was negative for metastasis. An ultrasound guided biopsy confirmed a grade 3 leiomyosarcoma.

He underwent a combined plastic and orthopedic surgery procedure involving tumour resection including lateral deltoid and half of bicep brachii muscles with preservation of the musculocutaneous nerve. He also had a 180-degree resection of humerus that was abutting the tumour. The orthopedic team performed simultaneous prophylactic intra-medullary nailing at the same time as tumour resection. Prophylactic intramedullary nailing of the humerus was performed at the same time as the resectional surgery so as to protect the weakened humerus from fracture, both in the early post-operative mobilisation period and also in the post-radiotherapy period. It enabled him to safely commence early active mobilisation with the sarcoma physiotherapists resulting in 100 degrees shoulder flexion and 90 degrees shoulder

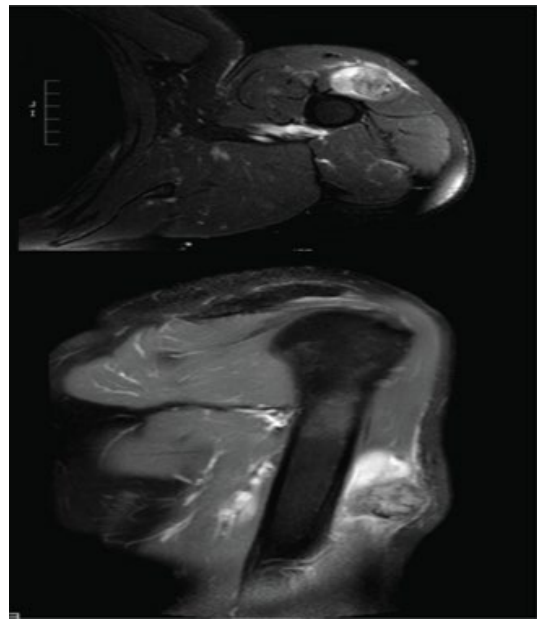

Figure 1: MRI of Leiomyosarcoma abutting humerus abduction at four weeks and fitness to return to work.

Histopathology revealed a grade 3 leiomyosarcoma that was completely excised. Recovery was uneventful and he began radiotherapy five weeks post-operatively (Figure 2).

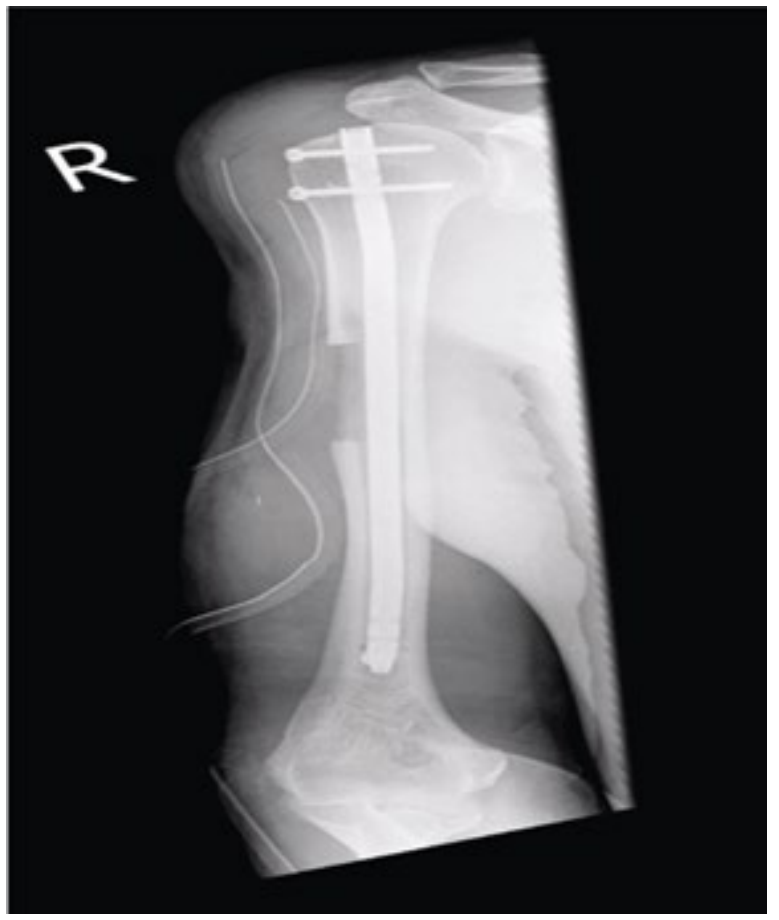

Figure 2: Post Operative Radiographs showing excised bony window and humeral nail

*Corresponding author: Holmes WJM, Department of Plastic Surgery, Alde Hey Children's Hospital, Eaton Road, West Derby, Liverpool, Merseyside L12 2AP, UK, Tel: 44 7590539096; E-mail: willjmholmes@gmail.com

Received April 18, 2014; Accepted May 24, 2014; Published May 27, 2014

Citation: Holmes WJM (2014) Simultaneous Soft Tissue Sarcoma Excision and Prophylactic and Bony Fixation of the Upper Limb: Expediting Radiotherapy and Reducing Fracture Risk. Anaplastology 3: 131. doi: 10.4172/2161-1173.1000131

Copyright: ( 2014 Holmes WJM. This is an open-access article distributed under the terms of the Creative Commons Attribution License, which permits unrestricted use, distribution, and reproduction in any medium, provided the original author and source are credited. 
Citation: Holmes WJM (2014) Simultaneous Soft Tissue Sarcoma Excision and Prophylactic and Bony Fixation of the Upper Limb: Expediting Radiotherapy and Reducing Fracture Risk. Anaplastology 3: 131. doi: 10.4172/2161-1173.1000131

Page 2 of 2

\section{Discussion}

Radiotherapy with limb-sparing surgery improves local control in high grade soft tissue sarcoma (STS) of the extremities [1]. Importantly, radiotherapy commenced within 3-6 weeks, once the surgical wound has healed has been shown to confer improved local recurrence rates and survival [2]. High-dose radiation is injurious to bone and is a known risk factor for the development of late fractures [3]. The incidence of femur fracture following STS resection and radiotherapy ranges from $5-9 \%[2,4-7]$. Little data exists on the rate of pathological fractures in the upper limb. One study shows a similar rate of fracture between upper limb and lower limb sarcomas at 5 years [8]. Upper limb pathological are of particular concern due the heavy function disability this confers and the lack of suitable soft tissue coverage and risk of wound breakdown any subsequent fixation risks. Post-operative brachy therapy (BRT) gives the opportunity to offer small volumes of radiation over a shorter period of time. But whilst BRT has shown promising results in terms of lower recurrence, it has failed to demonstrate a reduced fracture risk in long bones with periosteal stripping [9]. Intensity Modulated Radiotherapy (IMRT) permits dose contouring to enable accurate targeting of tumor cells whilst minimizing dose to uninvolved tissues. A recent large prospective phase-II clinical trial demonstrated no difference in total wound complications as compared with EBRT but of interest it did show a $0 \%$ fracture rate in long bone STS [10]. As of yet, there have been no comparative studies of EBRT and IMRT; thus, the potential advantages of IMRT remain speculative.

But despite these advances in radiotherapy the role of prophylactic fixation of long bones has been previously advocated for lower limb STS [11]. We show a case where prophylactic intramedullary nailing of the humerus at the time of primary surgery was deemed appropriate because of the periosteal and cortical bone removed during resection, and also because it was the dominant arm of a heavy built manual laborer.

This case highlights the importance of managing these complex cases in a multidisciplinary setting. Having a single surgical event allowed expedient radiotherapy to be delivered, as no secondary procedure was required. We therefore suggest that all STS that may require periosteal stripping or segmental removal of bone, and subsequent radiotherapy be discussed at a regional multidisciplinary meeting to plan a combined plastic and orthopedic surgical procedure. This will provide the best outcome whilst simultaneously reducing the risk of pathological fracture. Dedicated upper limb physiotherapy is essential not only in the immediate postoperative stage to minimize morbidity but also during radiotherapy to reduce the risk of contractures and maintain range of movement. This combined multidisciplinary approach will ultimately ensure the best possible oncological and functional outcome for these complex cases.

\section{References}

1. Habrand JL, Pechoux CLe (2004) Radiation therapy in the management of adult soft tissue sarcomas. Ann Oncol 187-191.

2. Keus RB, Rutgers EJ, Ho GH, Gortzak E, Albus-Lutter CE, et al. (1994) Limbsparing therapy of extremity soft tissue sarcomas: treatment outcome and longterm functional results. Eur J Cancer 30: 1459-1463.

3. Cannon CP, Lin PP, Lewis VO, Yasko AW (2008) Management of radiationassociated fractures. J Am Acad Orthop Surg16: 541-549.

4. Helmstedter CS, Goebel M, Zlotecki R, Scarborough MT (2001) Pathologic fractures after surgery and radiation for soft tissue tumors. Clin Orthop Relat Res 389: 165-172.

5. Dagan R, Indelicato DJ, McGee L, Morris CG, Kirwan JM, et al. (2012) The significance of a marginal excision after preoperative radiation therapy for soft tissue sarcoma of the extremity. Cancer 118: 3199-3207.

6. Blaes AH, Lindgren B, Mulrooney DA, Willson L, Cho LC, (2010) Pathologic femur fractures after limb-sparing treatment of soft-tissue sarcomas. J Cance Surviv 4: 399-404

7. Korah MP, Deyrup AT, Monson DK, Oskouei SV, Weiss SW, et al. (2012) Anatomic tumor location influences the success of contemporary limb-sparing surgery and radiation among adults with soft tissue sarcomas of the extremities. Int J Radiat Oncol Biol Phys82: 933-939.

8. Alektiar KM, Brennan MF, Singer S (2005) Influence of site on the therapeutic ratio of adjuvant radiotherapy in soft-tissue sarcoma of the extremity. Int $\mathrm{J}$ Radiat Oncol Biol Phys 63: 202-208.

9. Pisters PW, Harrison LB, Leung DH, Woodruff JM, Casper ES, et al. (1996) Long-term results of a prospective randomized trial of adjuvant brachytherapy in soft tissue sarcoma. J Clin Oncol 14: 859-868.

10. O'Sullivan B, Griffin AM, Dickie Cl, Sharpe MB, Chung PW, et al. (2013) Phase 2 study of preoperative image-guided intensity-modulated radiation therapy to reduce wound and combined modality morbidities in lower extremity soft tissue sarcoma. Cancer119: 1878-1884

11. Liu E, Sabolch A, Pak D, Biermann J, Ben-Josef E, et al. (2010) Femora fractures following limb-sparing surgery and radiotherapy for soft tissue sarcoma of the proximal lower-extremity: Importance of prophylactic intramedullary nail stabilization. Int J Radiat Oncol Biol Phys 78: 614-615. 